\title{
Otimização Discreta com Grafos no Ensino Médio
}

Discrete optimization with Graphs in High School

\section{Vanessa Henriques Borges ${ }^{1}$}

Ivail Muniz Junior²

\section{Resumo}

O objetivo desse artigo é apresentar o desenho de um produto educacional sobre combinatória e otimização, a partir de tarefas envolvendo otimização discreta com Grafos, voltado a sala de aula de matemática do Ensino Médio. Para isso, discutiremos as três etapas de desenvolvimento desse produto, que foram: (i) formulação de tarefas a partir de estudos recentes em educação matemática e das recomendações dos principais documentos curriculares vigentes no Brasil, aliadas às experiências curriculares de Portugal, Espanha e França sobre o tema, incluindo livros didáticos; (ii) implementação das tarefas com alunos de uma escola pública estadual na cidade Rio de Janeiro, Brasil; (iii) elaboração de um material didático para alunos - produto educacional - a partir dos resultados das etapas anteriores, incluindo uma investigação dos significados e conhecimentos produzidos pelos estudantes na fase de implementação.

Palavras-chave: grafos; otimização discreta; investigação Matemática; ensino médio.

\section{Abstract}

This article has the goal to present na educational product drawing about combinatory and optimization, from tasks about Discrete Optimizations with Graph, foccused on High School classroom. For this, we will discuss the three steps of the development of this product which were: (i) tasks' formulation by recent studies in Math Education and the main curricular documents' recommendations avaiable in Brazil, with curricular experiences from countries like Portugal, Spain and France about the theme, including didatic books; (ii) implementation of tasks with students of a public state school in the city of Rio de Janeiro, Brazil; (iii) elaboration of a didatic material for the students educational product - by the results from the steps before, including meanings' investigations and knowledge produced by the students in the implementation's phase.

Keywords: Graphs. Discrete Optimization. Mathematical investigation. High School.

\footnotetext{
${ }^{1}$ Especialista em Ensino de Matemática. Programa de Residência à Docência do Colégio Pedro II. Professora de Matemática da Rede Estadual de Ensino do Rio de Jane

2 Doutor em Engenharia de Produção pela COPPE-UFRJ. Docente efetivo do Departamento de Matemática do Colégio Pedro II - Campus Centro, e dos Programas de Pós-Graduação de Residência Docente, Mestrado em Ensino de Matemática e da Especialização em Educação Matemática do Colégio Pedro II. Lecture do Instituto Coppead de Administração da UFRJ. Professor da Escola Técnica João Luiz do Nascimento.
} 


\section{Introdução}

O estudo de combinatória na Educação Básica tem sido alvo de pesquisas em Educação Matemática em diversos países, principalmente nas últimas décadas, incluindo as realizadas no Brasil, dentre elas, Kenneth (2008); Neves; Bolinhas (2016); Silva (2009); Borba; Rocha; Azevedo (2015); Pessoa; Borba (2012). Entretanto, nossa revisão da literatura indicou que em tais estudos, há um foco nos processos cognitivos voltados para a combinatória de contagem, sendo escassos os trabalhos que abordam combinatória de existência e/ou otimização combinatória, incluindo os problemas envolvendo Grafos, dentre eles os trabalhos de Muniz (2007); Malta (2008); Deggeroni (2010).

Considerando uma perspectiva ampla de combinatória, conforme apresentada por Batanero, Godino e Navarro-Pelayo (1996), temos que há cinco tipos distintos de problemas combinatórios: a) existência - observação da possibilidade, ou não, de solução diante dos elementos dados e condições determinadas; b) enumeração - listagem de todos os subconjuntos de elementos que satisfazem as condições postas; c) contagem - determinação do número total de soluções, sem necessariamente listar todas; d) classificação - sistematização dos casos segundo critérios apropriados; e) otimização - busca da melhor condição para a obtenção de determinadas soluções para um problema.

Assim, buscou-se nesse trabalho abordar problemas combinatórios de existência e de otimização, sem desconsiderar, em algumas tarefas, as conexões e situações envolvendo a combinatória de contagem.

O objetivo desse artigo é apresentar o desenho de um produto educacional sobre combinatória e otimização, a partir de tarefas (que terão o mesmo sentido de atividade nesse texto) envolvendo otimização discreta com Grafos, voltado a sala de aula de matemática do Ensino Médio.

Apesar de tópicos em Grafos comporem programas de Matemática no ensino secundário de alguns países, dentre eles Portugal, Espanha e França, 
temos que no Brasil tais problemas raramente são abordados. Entretanto, a construção de propostas de intervenção na realidade e a tomada de decisão em problemas envolvendo matemática, incluindo os de natureza combinatória, são habilidades recomendadas nos principais documentos norteadores da Educação Básica, dentre eles os Parâmetros Curriculares Nacionais (PCN), as Orientações Curriculares para o Ensino Médio (OECM) e a Base Nacional Curricular Comum (BNCC).

Além disso, apesar dos conceitos de Grafos não fazerem parte dos programas de ensino no Brasil, o que suscita automaticamente a dúvida sobre a relevância de estudos e investigações sobre o ensino desse tema na Educação Básica, entendemos que existem várias conexões entre os problemas de otimização combinatória desenhados nesse trabalho e o ensino de combinatória na Educação Básica. Em outras palavras, é possível trabalhar essa temática dentro da análise combinatória do Ensino Médio. Esse Produto Final pretende contribuir para a ampliação das possibilidades de abordagens e tarefas sobre combinatória no Ensino Médio.

Finalizamos essa introdução dizendo que tal produto final foi desenhado no âmbito do Programa de Residência Docente (PRD) do Colégio Pedro $\|^{2}$, e implementado com alunos que cursaram a primeira série do Ensino Médio em 2017 em uma escola pública estadual situada na cidade do Rio de Janeiro. Tal pesquisa, que culmina com o Produto Final, é um dos requisitos desse programa de especialização que visa a formação continuada de professores, com forte viés na prática em sala de aula.

Para apresentarmos o desenho desse produto final, discutiremos as três etapas de desenvolvimento de seu desenvolvimento, que foram: (i) formulação de

\footnotetext{
2 O Programa de Residência Docente (PRD) do Colégio Pedro II é uma especialização, iniciada em 2011, que visa a formação continuada de professores que ensinam matemática, com forte viés na reflexão e prática em sala de aula. A Residência Docente pareia professores recém-formados (aqui denominados Residentes Docentes) com professores orientadores do Colégio Pedro II de modo a contribuir com uma formação complementar em questões de ensino-aprendizagem bem como em aspectos da vida escolar. Além disso, pretende possibilitar a aplicação de novas metodologias e estratégias pedagógicas aplicáveis à realidade da escola pública, incluindo a instituição de atuação do Professor Residente.
} 
tarefas a partir de estudos recentes em educação matemática e das recomendações dos principais documentos curriculares vigentes no Brasil, aliadas às experiências curriculares de Portugal, Espanha e França sobre o tema, incluindo livros didáticos; (ii) implementação das tarefas com alunos de uma Escola pública estadual na cidade Rio de Janeiro, Brasil; (iii) elaboração de um material didático para alunos - produto educacional - a partir dos resultados das etapas anteriores, incluindo uma investigação dos significados e conhecimentos produzidos pelos estudantes na fase de implementação.

\section{Revisão da Literatura}

A educação brasileira, de acordo com Búrigo (2012), sofreu modificações recentemente em vários aspectos. O maior desafio nesse momento é não só o ensino, mas em dar sentido e significado ao que é transmitido aos alunos. Isso devido à grande quantidade de informações que os alunos têm acesso e a velocidade com que isso ocorre. Se não mudar a maneira em que a aprendizagem é realizada, para essa geração o aprendizado tradicional, em sua maioria, não possui sentido ou valor. Esse é o maior desafio do momento.

Assim como o aluno, encontram-se professores formados através de uma graduação tradicional e engessados, muitas vezes, no ensino tradicional e com dificuldades para se renovar e se reconstruir como professor e mediador no ensino. Muitos simplesmente ficam parados inertes à mudança. Esse é outro desafio a ser enfrentado pelos docentes.

A área de matemática discreta é vasta apesar de ser emergente somente no século XX, e tem sido aplicada em variadas situações e problemas envolvendo deslocamentos, redes, planejamentos, logística, transporte dentre outras. Essa área também possui a característica de auxiliar o aluno a perceber que matemática não é somente álgebra ou geometria, além de ver aplicações práticas dessa área de conhecimento em temas como redes sociais, compras na internet, segurança dos dados pessoais, indução de consumo baseado nos rastros de 
seus caminhos virtuais, dentre outros.

Os documentos oficiais apontam para a importância da resolução de problemas, incluindo os de natureza combinatorial, principalmente aqueles envolvendo situações reais e com dados relacionados aos contextos em que vivem os estudantes. Os Parâmetros Curriculares Nacionais (BRASIL, 1997), por exemplo, defendem o papel da resolução de problemas na formação do aluno da educação básica, bem como na exploração problemas vividos no cotidiano e encontrados nas várias disciplinas. A Base Nacional Comum Curricular (BNCC) reforça a importância, já no $5^{0}$ ano do Ensino Fundamental, o trabalho com problemas de contagem e investigação matemática (na perspectiva do aluno investigador, que buscar descobrir padrões, relações, elaborar conjecturas e avaliar soluções para validá-las)

Temos também que na matriz de Referência do Exame Nacional do Ensino Médio (ENEM), a tomada de decisão e elaboração de propostas de intervenção na realidade são duas habilidades centrais presentes na matriz de avaliação, indicando que são importantes e desejáveis ao estudante concluinte do ensino médio.

Os trabalhos e pesquisas com grafos na educação básica no Brasil têm crescido, ainda que em um ritmo lento, uma vez que não fazem parte da grade curricular da educação básica. Entretanto, suas múltiplas aplicações, suas potencialidades relacionadas à resolução de problemas e à investigação matemática, suas possibilidades lúdicas, bem com as conexões com a parte da combinatória já estudada no Ensino Médio, continuam contribuindo para o surgimento de pesquisas e produtos finais com essa temática.

Em Jurkiewicz e Leventhal (2004), observa-se a proposta de execução de oficinas sobre Matemática Discreta no Ensino Médio, devido ao avanço tecnológico e como instrumento modificador do Ensino da Matemática. Dentre os resultados das oficinas, que ocorreram dentre outras Instituições no Colégio Pedro II, observa-se que apenas o uso do computador não é suficiente para o 
entendimento do discente nos instrumentos sociais, como por exemplo, o que acontece no Facebook ao buscar amizades ou ainda no Google Maps na busca pelo menor caminho.

Em Muniz (2007) destaca-se a importância de trabalhar Teoria de Grafos no Ensino Médio devido sua riqueza e amplitude para ser uma ferramenta no ensino de Análise Combinatória e Matrizes. O autor também reforça a possibilidade do uso de Grafos para explorar problemas que envolvam Otimização, com ou sem o auxílio de algoritmos. Ou seja, problemas básicos envolvendo noções iniciais de Grafos, que podem ser ferramentas na solução de questões que envolvam computação. Esse estudo também reforça que conceitos em grafos podem ser usados na busca de soluções para problemas que são resolvidos através de algoritmos ou computação. Assim, por exemplo, um aluno pode buscar soluções para problemas de transporte em que se gaste o mínimo de combustível. Esse tipo de solução possui caráter interdisciplinar, uma vez que trabalha com a diminuição da poluição ambiental. Essa dissertação, pioneira no Brasil na abordagem dos problemas do caminho mínimo e do caminho crítico no Ensino Médio, também foi base para algumas atividades realizadas ao longo desse trabalho.

Em Malta (2008) é proposto o uso da Teoria de Grafos através de atividades que envolvessem fatos históricos e com a intervenção satisfatória do orientador. O autor se pautou na metodologia de Resolução de Problemas com o apoio da escola particular em que a pesquisa foi realizada e que tem esse princípio.

Ferreira (2009) trabalha com Matemática Discreta, em particular com Teoria de Grafos, baseado na importância que este tema tem na área de computação, tema em expansão devido ao avanço tecnológico, e em pesquisa operacional. Nesse quesito trata grafo como modelagem matemática. A aplicação das atividades foi feita de maneira a não utilizar definições de grafos e sim aplicação de atividades em que os alunos tinham de resolver um problema da 
vida real através da análise da situação. De acordo com o autor, os alunos chegaram a conseguir resolver um problema através do auxílio da noção de coloração de grafos.

O trabalho de Pezeta (2013) apresenta o uso da Teoria de Grafos como ferramenta para resolução de problemas matemáticos e pautado em diversos níveis de conhecimento do conteúdo aprendido. Já o estudo de Costa (2013) buscou remediar as dificuldades na resolução de problemas que envolvem análise combinatória. Assim, defende o uso de grafos em problemas de moo que o aluno construa conceitos mais complexos gradativamente.

No trabalho de Müller (2015), temos que uma abordagem da Teoria dos Grafos no ensino fundamental. Aborda que esse tema é citado em alguns livros de ensino fundamental, mas como sendo um desafio e sem dizer que se trata de Grafo. Ele também relata sobre a importância do método pedagógico ser reciclado às novas demandas sociais e culturais do ambiente em que o aluno frequenta. Disserta sobre a aplicabilidade desta área de conhecimento em computação, transporte e problemas de otimização.

O trabalho de Mesquita (2015) defende a abordagem da Resolução de Problemas que envolvam a Teoria de Grafos. Os resultados evidenciaram a capacidade de os alunos desenvolverem argumentos matemáticos e encontrarem estratégias para resolverem problemas que foram propostos relacionados aos grafos.

Em Sá (2016) o trabalho desenvolvido é o de utilizar Teoria de Grafos como uma ferramenta histórica matemática para investigação de situações com o uso da tecnologia. A construção de uma maquete eletrônica foi a justificativa dessa investigação. Nela foi possível perceber a melhoria do entendimento das questões matemáticas, bem como a confusão realizada por alguns alunos entre Grafos e Geometria e a importância do conhecimento histórico-matemático para entendimento e resolução de problemas atuais.

A combinatória é um componente básico do raciocínio formal e constitui um recurso para a elaboração lógica proposicional nos adolescentes segundo 
Espinoza, Roa (2014). Contribui, além disso, no desenvolvimento do pensamento sistemático, pois na resolução de problemas combinatórios geralmente devemos examinar todas as possibilidades e enumerá-las. E dá oportunidades de fazer atividades características da matemática tais como realizar conjecturas, generalizar, questionar a existência de soluções, questões de otimização, entre outros, segundo Espinoza, Roa (2014). Ele cita que no currículo de educação secundária na Espanha, no momento de publicação desse trabalho, não havia papel significativo sendo mais abordados na construção do espaço amostral de um experimento e com aplicação no cálculo de probabilidades. O trabalho continua com a análise de diversos materiais didáticos. Como a Teoria de Grafos pode ser usada como ferramenta na resolução de problemas matemáticos que envolvam análise combinatória, dentre as questões analisadas nesse trabalho, Espinoza e Roa (2014 p.281) relata que o termo caminhos é usado no lugar de grafos. O interessante também é que nesse mesmo trabalho percebemos que o diagrama de árvore foi trabalhado em todos os livros analisados nesse artigo e que mostra o uso de grafo no ensino de análise combinatória ou do uso desse nas soluções de problemas de caráter combinatório.

Em Freitas (2017) aborda-se a resolução de problemas através do Teorema de Euler através da planificação dos grafos. Além de apresentar aplicações de problemas envolvendo o cotidiano dos alunos. Em Gualandi (2012) há atividades que podem ser usadas no ensino médio com o objetivo de relacionar matrizes e análise combinatória pela Teoria de Grafos. Em Guedes (2014) trabalha para que o aluno tenha capacidade de elaborar métodos de resolução de problemas e observação da Matemática Discreta em aplicações de outras áreas, não somente em contagem. Defende ainda a investigação de conceitos que envolvam grafos eulerianos e semieulerianos.

Também é possível observar em Neves, Bolinhas e Faria (2016), que países como Portugal já adotam a Teoria de Grafos na educação básica e para a fundamentação teórica há para leitura Lovász, Pelikán e Vesztergombi (2003). 
No estudo de Monego, Nascimento e Kozakevicius (2017), vemos o uso do Facebook como facilitador e contextualizado ao cotidiano dos alunos sobre o uso da Teoria de Grafos.

Olgin (2015) propõe atividades contextualizadas com temas atuais para tornar mais interessante o assunto. Onuchic e Allevato (2004) diz que é necessário mudar o centro do ensino que é feito no professor e focar no aluno, na produção de conhecimento e ação sem ter o professor no centro. Em Souza (2014) propõe atividades que abordam conceitos da Teoria de Grafos para o Ensino básico em que algumas utiliza notações sobre a Teoria de Grafos nas atividades propostas.

\section{Implementação e Investigação}

O interesse pela área de grafos começou na graduação com o projeto final neste tema, fruto de uma iniciação à docência voluntária com alguns algoritmos gulosos. Na especialização ao ter experiência nessa área, bem como o orientador ter trabalhado nessa área e ter enriquecido a visão de grafos em relação a educação e a partir de conversas e leituras da literatura surgiu o tema de trabalhar problemas de otimizar no ensino médio.

As tarefas foram desenhadas de modo que estimulassem e convidassem os alunos a:

(i) observar conexões entre a combinatória estudada no ensino médio e a otimização;

(ii) investigar padrões de natureza combinatória;

(iii) construir hipóteses;

(iv) desenvolver algoritmos e generalizar os resultados observados. 
No total foram 9 atividades aplicadas e analisados seus resultados. A primeira tarefa além de envolver um problema simples de otimização, teve como objetivo introduzir a noção de grafos, e foi baseada em Muniz, Jurkiewicz (2007). Duas turmas da tarde a realizaram, em média 22 alunos. Atividade com um grafo com casa, igreja, escola e supermercado e ruas entre esses locais. A atividade tinha por objetivo introduzir a ideia de grafo, observar como eles se sairiam. Respostas de menor caminho, maior caminho de força brutal, questão com possibilidades de ruas que o aluno poderia pegar, combinatória envolvida e representação do desenho através da noção de grafos em que vértices seriam os locais e as arestas as ruas. Não apresentaram dificuldades em realizar tal atividade.

A atividade seguinte era sobre tema caixeiro viajante. Atividade elaborada pelos autores após lerem os referenciais teóricos sobre o tema. Foram 4 turmas de 2 turnos e em média 15 alunos por turma. Atividade foi elaborada contextualizando os locais em torno da escola, com as distancias respectivas entre os locais representadas numa matriz e dados retirados do Google Maps. O objetivo da tarefa era investigar se os alunos conseguiam calcular as distâncias entre os locais, tentar descobrir a distância primeiro por força bruta e depois através do algoritmo do caixeiro viajante. A maior dificuldade apresentada foi lidar com os números decimais e ler as instruções. Os alunos apresentaram também noção intuitiva de distância, de direção e representação através de um grafo. Alguns alunos conseguiram desenvolver recursividade do algoritmo. Outros tentaram por força bruta. $\mathrm{E}$ alguns encontraram dificuldades de leitura da matriz.

A terceira tarefa era sobre caminho mínimo - algoritmo de Dijkstra - Mais uma atividade contextualizada com a realidade escolar com pontos ao redor da escola. Duas turmas e em média 12 alunos. Esta se encontra mais detalha a seguir.

A quarta tarefa trabalhava com o algoritmo de Bellman Ford - duas turmas fizeram a atividade, em média 9 alunos. Atividade trata de uma aposta entre dois 
irmãos. O vencedor do jogo receberia o produto entre $R \$ 50,00$ e o resultado em dinheiro para comprar sua coleção. Tratava-se de um grafo direcionado e com arestas negativas envolvidas. $O$ interessante é que alguns alunos perceberam nos caminhos direcionados ciclos e perguntavam se podiam passar mais de uma vez por este. Tiveram dificuldades em seguir o passo a passo do algoritmo.

A quinta tarefa trata de emparelhamento perfeito - duas turmas com média de 14 alunos realizaram a tarefa. A primeira etapa trata de um site de relacionamentos que detecta a compatibilidade entre pessoas e gera um mapa de combinações. Primeiro pedia que o aluno de acordo com as combinações de pares possível apresentasse uma solução viável sem ninguém ficar sozinho. Eles não apresentaram dificuldades. Na segunda etapa para construir outra possível solução muitos descartaram as combinações geradas pelo site e combinaram aleatoriamente, por falta de leitura. Na segunda tarefa eram casais com gostos distintos que iam ao cinema. Para que todos pudessem ir ao cinema, o desenvolvimento do emparelho perfeito é explicitado na atividade. No passo de excluir uma das arestas alguns alunos ficaram perdidos, mas melhoraram bastante o processo de recursividade.

A sexta tarefa é sobre fluxo máximo com o uso do algoritmo de Ford Fulkerson - duas turmas em média 17 alunos. Outra atividade com contextualização ao redor da escola. Trata de um incêndio e para apagar o fogo é necessário usar hidrômetro que recebe agua de vários canos com distintas capacidades. Cada cano possui uma direção e esta é representada por arestas com setas. Esta junto à atividade do caminho mínimo foi a que os alunos se mostraram mais interessados e pareceram gostar. $O$ desenvolvimento de recursividade foi melhor em relação as atividades anteriores. A dificuldade apresentada foi de escrever o passo a passo das contas realizadas e de perceber que quando a capacidade de um cano se esgotava ainda que outro tivesse capacidade ele não teria como passar por ali. 
A sétima tarefa aborda as ideias de grafo Euleriano e otimização, e foi adaptada de Muniz (2007, p. 70), onde levou-se em consideração os locais ao redor da escola já utilizados nas tarefas anteriores. A primeira atividade pede que os alunos passem por todas as ruas do mapa representado por um grafo sem repetir sem nenhuma rua. As respostas foram muito variadas e alguns não entenderam a ideia de não repetir rua e tentaram não repetir os lugares. Essa foi uma das atividades que eles mais tiveram dificuldades de compreender. $\mathrm{Na}$ segunda parte principalmente na segunda parte em que pedimos para que falassem o grau de cada vértice e mesmo falando que era quantas ruas saiam de cada lugar muitos não entenderam esse conceito.

A oitava tarefa abordava coloração de grafos - 3 turmas com média de 21 alunos - a atividade envolve a noção de coloração de arestas e vértices. Foi a atividade mais intuitiva que os alunos apresentaram para desenvolver. As primeiras atividades envolviam coloração de vértices a fim de usar a quantidade mínima de cores. As seguintes envolviam a coloração total (vértices e arestas). E finalmente a última questão era para colorir o mapa brasileira usando a quantidade mínima de cores. Alguns tentaram usar a quantidade máxima de cores. Não perceberam a relação com grafos, tivemos que explicar e levaram como diversão e atividade lúdica.

A última atividade envolve teorema de Euler e caminho Hamiltoniano - 3 turmas, 18 alunos em média - A primeira tarefa foi retirada dos referenciais teóricos e envolve um assassinato. A maioria dos alunos não associou o problema com grafos, pois não leram com devida atenção a questão ou focaram em detalhes sem relacionar com a ideia de grafos para solucionar o problema. Já a segunda tarefa envolvia encontrar um caminho que não repetisse vértice e passasse por todos eles. A maioria encontrou a solução.

Após a aplicação nosso objetivo é reunir todos esses dados, impressões e falhas encontradas no desenvolvimento das tarefas e redesenhá-las a fim de criar um caderno de questões que seja acessível a outros pesquisadores e docentes 
como mais uma ferramenta e fonte de pesquisa para seus planos de aula, adequando o que for necessário à suas realidades.

Dentre as tarefas realizadas, destacamos com mais detalhes nessa parte a tarefa do caminho mínimo, que envolve o algoritmo de Dijkstra. A Figura 1.1 foi utilizada nesta tarefa para contextualizar o local onde a personagem Lucia morava e os respectivos locais em torno da escola por onde deveria passar. Uma das tarefas se referia a uma menina que gostaria de passar por vários locais propostos na atividade de modo que gastasse o menor tempo possível. Os locais foram elaborados de acordo com o local em que a escola se encontra e pontos chave ao entorno desta. Ou seja, tivemos a preocupação de contextualizar a atividade com a realidade dos alunos daquela turma. Essa atividade foi aplicada em duas turmas de primeiro ano com uma turma de 15 alunos e 9 alunos na outra.

Figura 1.1 - Uma situação real envolvendo o problema do caminho mínimo

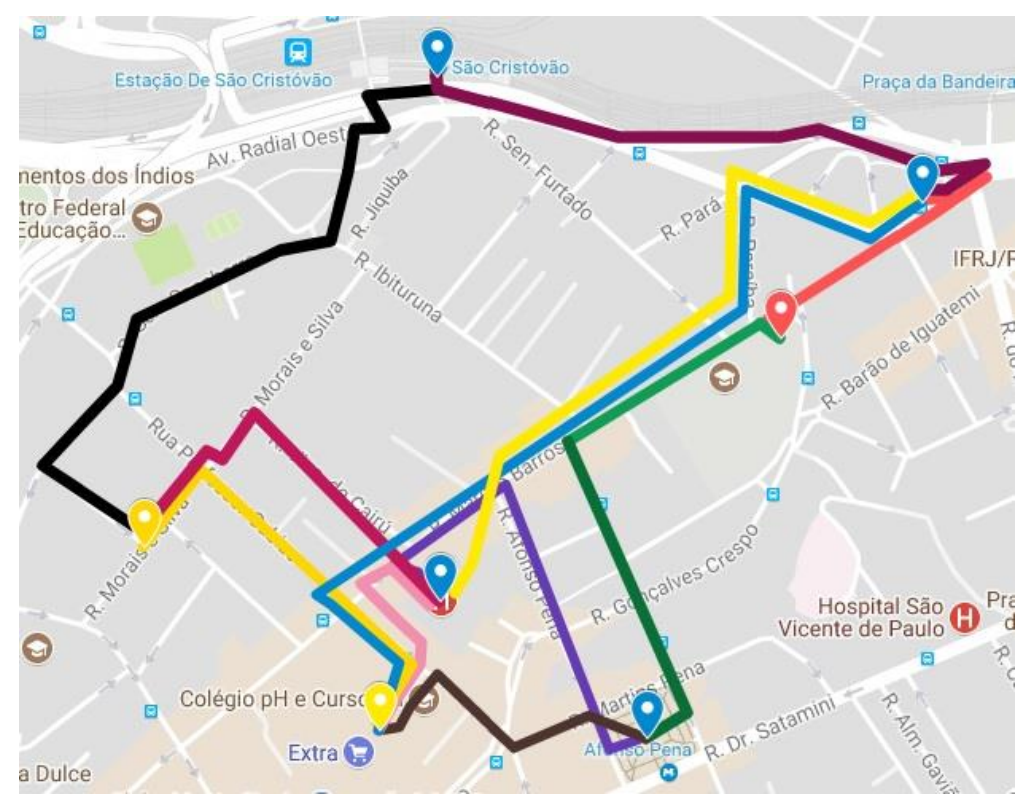

Fonte: Elaborada pelos autores. 
Figura 1.2 - Um modelo em grafos para a situação apresentada na Fig. 1.1

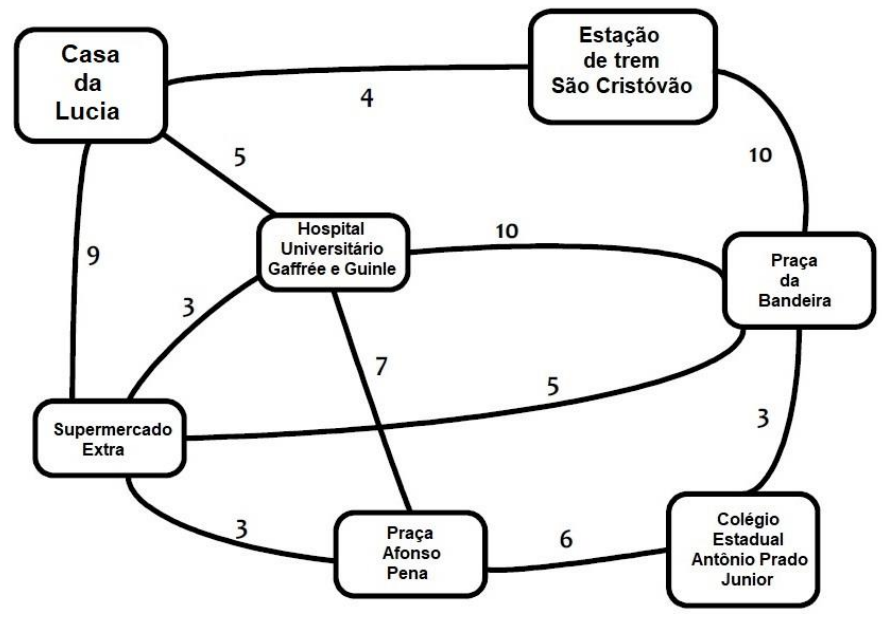

Fonte: Elaborada pelos autores

Na Figura 1.2, modificada a partir da tarefa apresentada em Muniz (2007, p.85), os valores numéricos representam o tempo que a personagem Lucia leva para andar desde sua casa até aquele ponto. Os alunos não encontraram dificuldades em responder na tarefa qual era a distância entre dois locais. Ao perguntarmos quanto tempo Lucia levaria de sua casa até a Praça da Bandeira, os alunos escolheram o caminho que leva 14 minutos. Nenhum relatou o que leva 15 minutos e que passa pelo Hospital Universitário. Mas um aluno escolheu um caminho mais longo que passa pelo Hospital, pela Praça Afonso Pena, pelo Colégio e finalmente à Praça da Bandeira totalizando 21 minutos. Se analisarmos as respostas como um todo, observamos que apesar de não termos colocado nenhuma restrição no caminho que a personagem poderia seguir, a maioria dos alunos considerou o caminho que levasse menos tempo, o que é algo natural para o ser humano no sentido de buscar caminhos ou alternativas, pois sempre buscamos aquilo que dá menos trabalho ou que é mais rápido.

Posterior a essa questão, pedimos aos alunos que encontrassem 3 caminhos possíveis da Casa da Lucia até o Colégio, que os descrevessem e colocassem o tempo levado. Nessa questão os alunos apresentaram uma riqueza de diferentes respostas e apesar de não trabalhar com fórmulas. $O$ aspecto lúdico e investigativo dessa tarefa combinatória contribuiu para a variedade de caminhos 
apresentados pelos estudantes. Outro ponto interessante a ser levantado é que muitos representaram os locais através de letras e os caminhos escolhidos através de setas. Ou seja, apesar de não saberem o que é um Grafo, utilizaram de maneira natural e intuitiva esse conceito.

Da mesma maneira a noção do algoritmo de caminho mínimo foi trabalhada nessa atividade e na segunda parte da tarefa, colocamos o passo a passo de como os alunos deveriam fazer para encontrar o menor caminho. Foi notável a dificuldade em ler e interpretar. A todo tempo nos pediam ajuda para entender o que era para ser feito. Ao invés de lerem a questão, imediatamente pediam ajuda. Isso mostra a deficiência e falta de hábito da leitura. Após ajudarmos, eles conseguiram encontrar a solução correta. Interessante que alguns colocaram setas para direcionar o caminho que tomaram e mais uma vez intuitivamente utilizaram a noção de grafo direcionado sem saber que esse conceito existe.

Os alunos na atividade de encontrar o menor caminho, em sua maioria, usaram força bruta, por não lerem os passos a serem seguidos. Aqueles que conseguiram seguir os passos foi com nosso auxílio. Houve também os alunos que após perceberem o processo recursivo do algoritmo ajudaram a outros colegas. Isto melhorou na questão seguinte que pedia para encontrar o caminho que levasse o maior tempo. Nesta a maioria dos alunos conseguiu desenvolver a recursividade do algoritmo.

Assim como em Espinoza e Roa (2014), nessa atividade, como em outras propostas, os alunos utilizaram a palavra caminho e que implicitamente significa aresta. Isto é mais uma evidência de que Grafos é um campo matemático natural e sem a necessidade, no Ensino Médio, de apresentar aos alunos com alto rigor matemático a estrutura e propriedades dessa área. Caso isso acontecesse, ela perderia o valor intuitivo e facilitador na resolução de problemas matemáticos que envolvem combinatória. 


\section{Considerações finais.}

Nesse artigo vimos que o Ensino de Combinatória no Brasil é predominantemente baseado nas técnicas de contagem, sendo os problemas de existência e otimização subutilizados na educação básica, apesar de tão ricos e potencialmente importantes no desenvolvimento de habilidades tais como a análise, elaboração de propostas e soluções e a tomada de decisão.

Apresentamos assim nesse texto o desenho de um produto final com um conjunto de nove atividades que visavam contribuir para a reflexão sobre esse desperdício de oportunidades, bem como ajudar na redução dessa lacuna. Tais atividades foram desenhadas e implementadas com alunos do Ensino Médio, e convidaram os estudantes a observar conexões entre a combinatória estudada no ensino médio e a otimização; investigar padrões de natureza combinatória; construir hipóteses; desenvolver algoritmos e generalizar os resultados observados. Além disso, tais tarefas levaram em consideração a contextualização com problemas da realidade dos alunos que envolvessem a noção de algoritmos, que está presente em diversas tecnologias, como na busca pela menor rota em aplicativos variados.

$\mathrm{Na}$ fase de implementação identificamos que as tarefas cumpriram parcialmente os objetivos traçados. A investigação de caminhos e a busca por soluções otimizadas estiverem conectadas estratégias de enumeração e técnicas de contagem, como por exemplo, nas tarefas 14 , e 7.

$\mathrm{Na}$ implementação, também observamos que os estudantes utilizaram noções da Teoria de Grafos de maneira intuitiva e sem terem tido acesso às definições e à estrutura, tais como caminho, fluxo, orientação, dentre outros. Essa característica pode ser um indício de que determinados problemas relacionados à Teoria de Grafos podem ser explorados na educação básica, e também podem ser um meio facilitador do ensino de análise combinatória. 
A construção de hipóteses com os estímulos gerados por problemas de combinatória de existência também foi identificada na realização das tarefas propostas. As perguntas: "será que existe um melhor?"; "esse é realmente o máximo?" ou ainda "como podemos garantir que esse é o menor?", e também "será que existe uma solução?", contribuíram para que algumas conjecturas fossem emergindo, em velocidades variadas, ao longo da investigação.

Observamos também a relação que muitos alunos fazem entre menor caminho com o uso mínimo de arestas. No caso das ruas e dos locais por onde passar, foi muito intuitivo pelas respostas que observam a quantidade mínima de arestas ou com menor valor. Outra questão é a utilização recorrente da palavra um caminho passa por um determinado lugar.

Durante a realização das nove tarefas aplicadas identificamos dificuldades de leitura e atenção dos enunciados apresentados. Foi necessária a intervenção do professor para a compreensão dos alunos em diversos momentos. Em outras pudemos detectar também dificuldades nas operações básicas com números decimais. Assim, foi possível identificar características e dificuldades da parte operacional dos alunos, relacionadas à aritmética, algo que não era nosso objetivo, mas que emergiu durante a realização das tarefas.

Dentre as contribuições que esse trabalho nos proporciona, está a percepção de como conceitos da Teoria de Grafos são intuitivos aos alunos e como podem auxiliar no desenvolvimento do Raciocínio Combinatório e apresentar outras abordagens de combinatória diferente das tradicionais focadas em fórmulas ou problemas específicos, sem explorar todo o campo vasto e rico desta área, visando o desenvolvimento de habilidades dos cidadãos que terão que enfrentar os grandes desafios do século XXI.

\section{Referências}

BRASIL. Ministério da Educação. Base Nacional Comum Curricular - BNCC $2^{2}$ versão. Brasília, DF, 2017. 
BORBA, Rute Elizabete de Souza Rosa; ROCHA, Cristiane de Arimatéa; AZEVEDO; Juliana. Estudos em Raciocínio Combinatório: investigações e práticas de ensino na Educação Básica. In Bolema [on line], Rio Claro (SP), v. 29, n. 53, p. 1348-1368, dez. 2015

DEGGERONI, R. Uma introdução à teoria dos grafos no ensino médio. Trabalho de conclusão de curso. UFRGS. 2010.

BÚRIGO, Elisabete Zardo. A matemática na Escola - Novos conteúdos, novas abordagens. Série Educação a Distância. UFRGS, 2012.

COSTA, Elisângela Ribeiro Silva. Uma proposta de ensino de análise combinatória para alunos do ensino médio. 107f. Dissertação (Mestrado). Programa de Pósgraduação em Matemática, Universidade Federal de Lavras, 2013.

ESPINOZA, Jonathan; ROA, Rafael. La combinatoria en libros de texto de matemática de educación secundaria en España. In M. T. González, M. Codes, D. Arnau y T. Ortega (Eds.), Investigación en Educación Matemática XVIII (pp. 277-286). Salamanca: SEIEM. 2014.

FERREIRA, Gessé Pereira. A Viabilidade do ensino de Matemática Discreta no Ensino Médio usando modelagem. 94 f. Dissertação (Mestrado). Mestrado Profissional em Ensino de Ciências e Matemática, Universidade do Grande Rio (UNIGRANRIO), 2009.

FREITAS, Janderson dos Santos de. O Teorema de Euler para Poliedros e a Topologia dos Grafos no Ensino Médio. Dissertação (Mestrado). Universidade Federal do Maranhão, 2017.

GUALANDI, Jorge Henrique. Investigações Matemática com grafos no Ensino Médio. 117 f. Dissertação (Mestrado). Programa de Pós-graduação em Ciências e Matemática. Pontifícia Universidade Católica de Minas Gerais (PUC-MG), 2012.

GUEDES, Victor Emanuel Pinto. Uma abordagem para o ensino da teoria dos grafos no Ensino Médio. Dissertação (Mestrado). Mestrado Profissional em Matemática em Rede Nacional. Universidade Federal de Juiz de Fora, 2014.

KAPUR, J. N. Combinatorial analysis and school mathematics. Educational Studies in Mathematics Education, 3(1), 111-127.

KENNETH, R. Chelst; EDWARDS, Thomas G. ¿Avanzará esta fila alguna vez? Aplicaciones de la Investigación de Operaciones. Madri: Editorial Universitaria, 2008.

LOVÁSZ, L.; PELIKÁN J.; VESZTERGOMBI, K. Matemática Discreta. Coleção do Professor de Matemática. Rio de Janeiro: Sociedade Brasileira de Matemática, 2003.

MALTA, Glacia Helena Sarmento. Grafos no Ensino Médio - Uma Inserção Possível. 154 f. Dissertação (Mestrado). Mestrado Profissionalizante em Ensino de Matemática. Universidade Federal do Rio Grande do Sul (UFRGS), 2009. 
MESQUITA, Daniel da Rosa. Resolução de problemas relacionados à teoria de Grafos no Ensino Fundamental. 97 f. Dissertação (Mestrado). Mestrado Profissional em Ensino de Matemática, Universidade Federal do Rio Grande do Sul, 2015.

MONEGO, Vinicius Schmidt; NASCIMENTO, Monique Rubenich; KOZAKEVICIUS, Alice. Aprendendo grafos através do facebook. Universidade Federal de Santa Maria, 2017.

MUNIZ, Ivail Junior. Encontrando, minimizando e planejando percursos: uma introdução à teoria dos grafos no Ensino Médio. 146 f. Dissertação (Mestrado). Mestrado profissional em Ensino de Ciências e Matemática. Centro Federal de Educação Tecnológica Celso Suckow da Fonseca (CEFET-RJ), Rio de Janeiro, 2007.

MUNIZ, Ivail Junior; JURKIEWICZ, Samuel. GRAFOS: Conceitos e Contextos para o ensino médio. Material Didático - Produto final de Mestrado Profissional, 2007.

MUNIZ, Ivail Junior; MARINHO, Fernando Celso Villar, Vídeos da TV Escola - Dicas Pedagógicas - Matemática em toda parte II - Episódio: "Matemática na Cidade", 2015.

NEVES, Maria Augusta Ferreira; BOLINHAS, Sandra; FARIA, Luísa. Preparação para o exame final nacional - Matemática aplicada às Ciências Sociais, 11ํANO. Porto Editora. Lisboa, 2016.

OLGIN, Clarissa de Assis. Critérios, possibilidades e desafios para o desenvolvimento de temáticas no currículo de matemática do ensino médio. 266 f. Doutorado em Ensino de Ciências e Matemática. Universidade Luterana do Brasil, Canoas, 2015.

ONUCHIC, Lourdes de la Rosa; ALLEVATO, Norma Suely Gomes. Novas reflexões sobre 0 ensino-aprendizagem de matemática através da resolução de problemas. Educação matemática: pesquisa em movimento. São Paulo: Cortez, p. 212-231, 2004.

BRASIL, 1997. Parâmetros Curriculares Nacionais (PCN). Matemática. Volume 3. 1997.

PEZETA, Jefferson Ricart. Resolução de problemas em contextos de ensino de Matemática: uma abordagem por meio da Teoria dos Grafos. $153 \mathrm{f}$. Dissertação (Mestrado). Mestrado Profissional em Educação Matemática. Pontifícia Universidade Católica de São Paulo (PUC-SP), 2013.

SA, Laulo Chagas. Construção e utilização de maquete eletrônica para ensino de Grafos: aprendizagens discentes a partir de uma abordagem histórico-investigativa.150 f. Dissertação (Mestrado). Mestrado Profissional em Educação em Ciências e Matemática. Instituto Federal de Educação, Ciência e Tecnologia do Espírito Santo, 2016.

SILVA, Liliana Mota Cardoso Marques da. A Teoria dos Grafos no Ensino. Dissertação (Mestrado). Universidade Portucalense Infante D. Henrique, Portugal, 2009.

SOUZA, Renato Ferreira de. Resolução de problemas via teoria de grafos. $48 \mathrm{f}$. Dissertação (Mestrado). Mestrado Profissional em Matemática em Rede Nacional. Universidade de São Paulo (USP), 2014. 